\title{
Apical myectomy: A new surgical technique for management of severely symptomatic patients with apical hypertrophic cardiomyopathy
}

\author{
Hartzell V. Schaff, MD, ${ }^{a}$ Morgan L. Brown, MD, ${ }^{a}$ Joseph A. Dearani, MD, ${ }^{a}$ Martin D. Abel, MD, \\ Steve R. Ommen, MD, ${ }^{c}$ Paul Sorajja, $M D,{ }^{c}$ A. Jamil Tajik, MD, ${ }^{d}$ and Rick A. Nishimura, MD $^{\mathrm{c}}$
}

\begin{abstract}
Objective: Apical hypertrophic cardiomyopathy is a morphologic variant in which the hypertrophy is primarily localized to the apex of the left ventricle. A subset of patients have progressive, drug-refractory diastolic heart failure with severely limiting symptoms caused by low cardiac output. Heart transplantation has been the only therapeutic option available for such patients. This study analyzes clinical and hemodynamic outcomes of a novel surgical technique to improve diastolic filling by means of left ventricular cavity enlargement.
\end{abstract}

\begin{abstract}
Methods: Forty-four symptomatic patients underwent apical myectomy to augment left ventricular end-diastolic volume. Myectomy was performed through an apical incision, and hypertrophic muscle was excised at the apex and midventricle. Information from a prospective database was supplemented by surveys, patient contact, and medical records.
\end{abstract}

Results: The mean age of the patients was $50 \pm 17$ years, and $66 \%$ were women. All patients were severely limited with dyspnea, $61 \%$ had angina, and 59\% had syncope/presyncope. Ninety-one percent of patients were in New York Heart Association class III or IV. A mean of $16 \pm 7 \mathrm{~g}$ of muscle was removed. Preoperative and postoperative hemodynamic catheterization $(\mathrm{n}=14)$ showed a decrease in left ventricular end-diastolic pressure from $28 \pm 9$ to $24 \pm 7 \mathrm{~mm} \mathrm{Hg}(P=.002)$ and an increase in end-diastolic volume index from $55 \pm 17$ to $68 \pm 18 \mathrm{~mL} /$ $\mathrm{m}^{2}(P=.003)$. Invasive measurements of stroke volume increased from $56 \pm 17$ to $63 \pm 19 \mathrm{~mL}(P=.007)$. Of the 42 patients who survived to hospital discharge, 41 had improvement in symptoms. Mean peak maximum oxygen consumption with exercise $(\mathrm{n}=5)$ increased from $13.5 \pm 4.4$ to $15.8 \pm 4.6 \mathrm{~mL} / \mathrm{kg}$ per minute. Survival at 1,3 , and 5 years was $95 \%, 81 \%$, and $81 \%$, respectively. At follow-up of $2.6 \pm 3.1$ years, $23(74 \%)$ patients were in New York Heart Association class I or II. One patient underwent heart transplantation 5 years after apical myectomy.

Conclusions: Apical myectomy improves functional status by decreasing left ventricular end-diastolic pressure, improving operative compliance, and increasing stroke volume. This procedure might be of value in other patients with hypertrophic cardiomyopathy who have severe hypertrophy and small left ventricular end-diastolic volume. (J Thorac Cardiovasc Surg 2010;139:634-40)

Apical hypertrophic cardiomyopathy (ApHCM) is a rare morphologic variant of hypertrophic cardiomyopathy (HCM), with the hypertrophy primarily localized in the apex of the left ventricle (LV). ${ }^{1-6}$ Generally, ApHCM has been considered a benign condition, with few or mild symptoms in most patients and favorable long-term survival. ${ }^{6-10}$

From the Division of Cardiovascular Surgery, ${ }^{a}$ the Division of Cardiovascular and Thoracic Anesthesia, ${ }^{\mathrm{b}}$ and the Division of Cardiovascular Diseases, ${ }^{\mathrm{c}}$ Mayo Clinic, Rochester, Minn, and the Division of Cardiovascular Diseases, ${ }^{\mathrm{d}}$ Mayo Clinic, Scottsdale, Ariz.

Disclosures: None.

Read at the Eighty-ninth Annual Meeting of The American Association for Thoracic Surgery, Boston, Mass, May 9-13, 2009.

Received for publication May 8, 2009; revisions received June 10, 2009; accepted for publication July 5, 2009.

Address for reprints: Hartzell V. Schaff, MD, Cardiovascular Surgery, Mayo Clinic, 200 First St SW, Rochester, MN 55905 (E-mail: schaff@mayo.edu). 0022-5223/\$36.00

Copyright (C) 2010 Published by Elsevier Inc. on behalf of The American Association for Thoracic Surgery

doi:10.1016/j.jtcvs.2009.07.079
Some investigators, however, have reported a subset of patients with symptoms of fatigue, angina, or dyspnea, and still others with arrhythmia or even sudden death., ${ }^{2,3,11-13}$ Treatment options for symptomatic patients with ApHCM are limited, and clinical experience has shown that response to medical therapy is poorer than that for patients with obstructive HCM.

In this report we describe our experience with a surgical approach to the treatment of ApHCM that involves the excision of a portion of the thickened muscle to permit greater filling of the LV in diastole. We evaluated hemodynamics, including the effect of the procedure on left ventricular end-diastolic volume (LVEDV), end-diastolic pressure, and stroke volume (SV), and we assessed late patient survival and functional status.

\section{MATERIALS AND METHODS}

After approval of the institutional review board, we reviewed the clinical, hemodynamic, and imaging data of 45 patients with ApHCM who had 


$$
\begin{array}{ll}
\text { Abbreviations and Acronyms } \\
\text { ApHCM } & =\text { apical hypertrophic cardiomyopathy } \\
\mathrm{HCM} & =\text { hypertrophic cardiomyopathy } \\
\mathrm{ICD} & =\text { implantable cardioverter defibrillator } \\
\mathrm{LV} & =\text { left ventricle } \\
\mathrm{LVEDV} & =\text { left ventricular end-diastolic volume } \\
\mathrm{MRI} & =\text { magnetic resonance imaging } \\
\mathrm{NYHA} & =\text { New York Heart Association } \\
\mathrm{PPM} & =\text { permanent pacemaker } \\
\mathrm{SV} & =\text { stroke volume } \\
\mathrm{VO}_{2 \max } & =\text { peak oxygen consumption }
\end{array}
$$

undergone apical myectomy at Mayo Clinic, Rochester, Minnesota, between September 1993 and January 2009. One patient who refused research authorization was excluded from analysis. Diagnostic studies were performed as clinically indicated and evolved during this 15-year experience. The diagnosis of ApHCM was established in all patients by means of transthoracic echocardiographic analysis, which demonstrated localized hypertrophy at the apical and middle levels of the LV. Additional preoperative testing included exercise testing with measurement of peak oxygen consumption $\left(\mathrm{VO}_{2 \max }\right)$, LV pressure measurements with high-fidelity manometer-tipped catheters (Figure 1), and simultaneous left ventriculographic analysis; more recently, magnetic resonance imaging (MRI) was conducted, including measurement of LV volumes in select patients (Figure 2).

Operations were performed through a standard median sternotomy. Patients were started on cardiopulmonary bypass (normothermia at $2.4 \mathrm{~L}$. $\min ^{-1} \cdot \mathrm{m}^{-2}$ ) by using direct aortic cannulation and a single 2 -stage venous cannula. Cold antegrade blood cardioplegia $(1000-1200 \mathrm{~mL})$ was used for myocardial protection. In each patient an apical ventriculotomy was made lateral to the left anterior descending artery (Figure 3). The apex of the heart was obliterated with muscle, and initial myectomy was performed along the septum. After identification of the anterolateral and posteromedial papillary muscles, myectomy was extended to other areas with the goal of enlarging the apical third of the LV. The ventricular cavity was also augmented by means of division of hypertrophied trabeculae and, in some patients, by means of careful shaving of the hypertrophied papillary muscles. The resec-

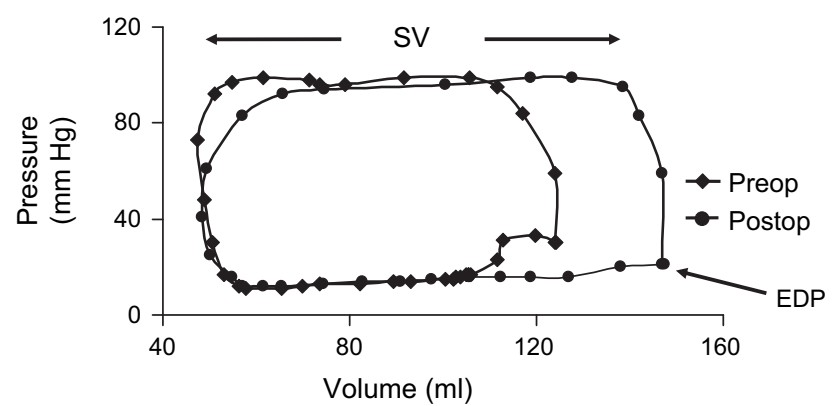

FIGURE 1. Pressure-volume loops in a patient with apical hypertrophic cardiomyopathy before (A) and after (B) surgical intervention. Pressure recordings were taken with high-fidelity micromanometer catheters (Millar Instruments, Houston, Tex); left ventricular volumes were calculated from contrast ventriculograms. Apical myectomy resulted in an increase in stroke volume $(S V)$ and a larger left ventricular end-diastolic volume at lower enddiastolic pressure $(E D P)$, suggesting improved left ventricular compliance after the operation. Preop, Preoperatively; Postop, postoperatively.
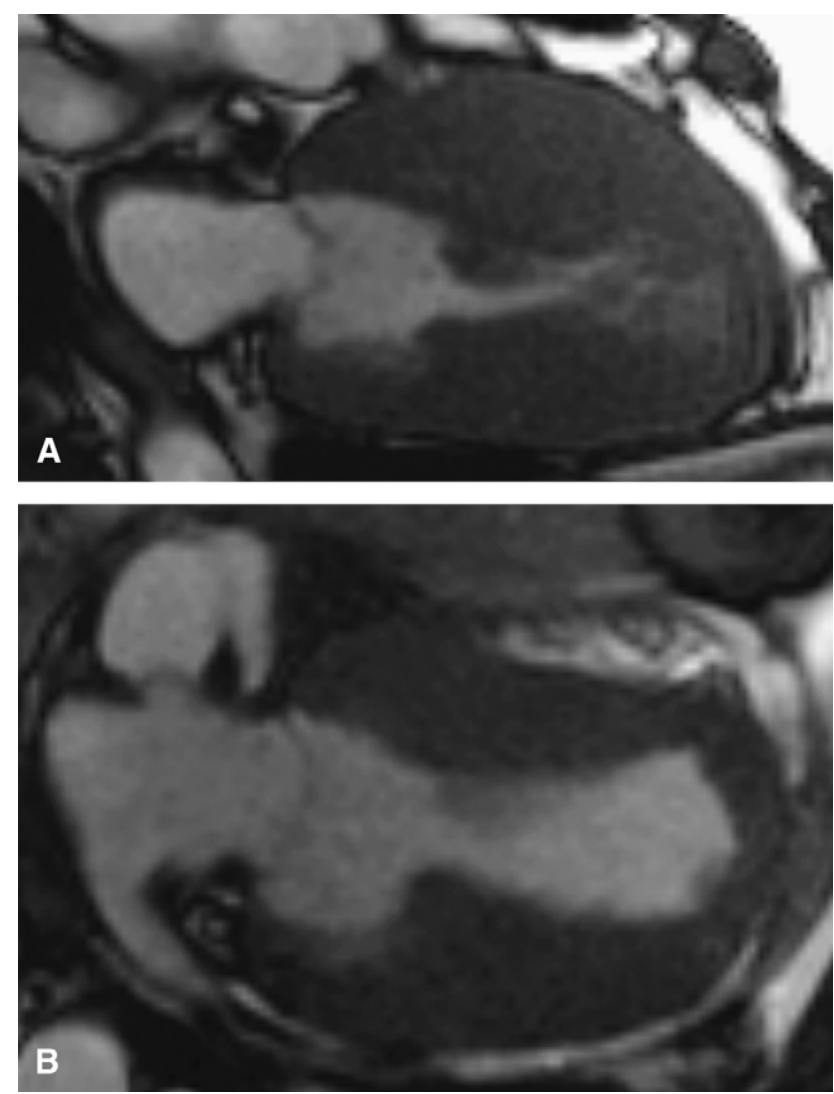

FIGURE 2. Cardiac magnetic resonance imaging demonstrates apica hypertrophic cardiomyopathy during diastole before (A) and after (B) apical myectomy that substantially enlarged the left ventricular cavity.

tion removed the mass of myocardium filling the apex of the heart, leaving a wall thickness of 10 to $12 \mathrm{~mm}$. After resection, the apical ventriculotomy was closed in 2 layers over strips of felt. In 7 patients additional muscle was removed from the LV outflow tract through the aortic valve after an aortotomy. Other concomitant procedures were performed as indicated.

Patients underwent transthoracic echocardiographic analysis, hemodynamic cardiac catheterization, or MRI before hospital dismissal and at late follow-up, as clinically indicated. Patients' records were reviewed for available follow-up information. In addition, patients were contacted through survey follow-up, and vital status was confirmed by using Accurint (LexisNexis, New York, NY [www.accurint.com]).

Statistics were performed with SAS statistical software (SAS Institute, Inc, Cary, NC). Results for continuous data are reported as means \pm standard deviations or medians and ranges, as appropriate, and results for categorical data are reported as numbers (percentages) for each category from the observed total. Paired $t$ tests were used to compare continuous parameters between preoperative, dismissal, and late hemodynamic measurements. Kaplan-Meier survival methods were used to assess mortality.

\section{RESULTS}

Forty-four patients underwent apical myectomy between September 1993 and January 2009. The mean age of the patients was $50 \pm 17$ years, and $66 \%$ were women (Table 1). All patients were symptomatic at the time of the operation despite aggressive medical therapy. Systolic function was preserved in all patients, and the mean ejection fraction 

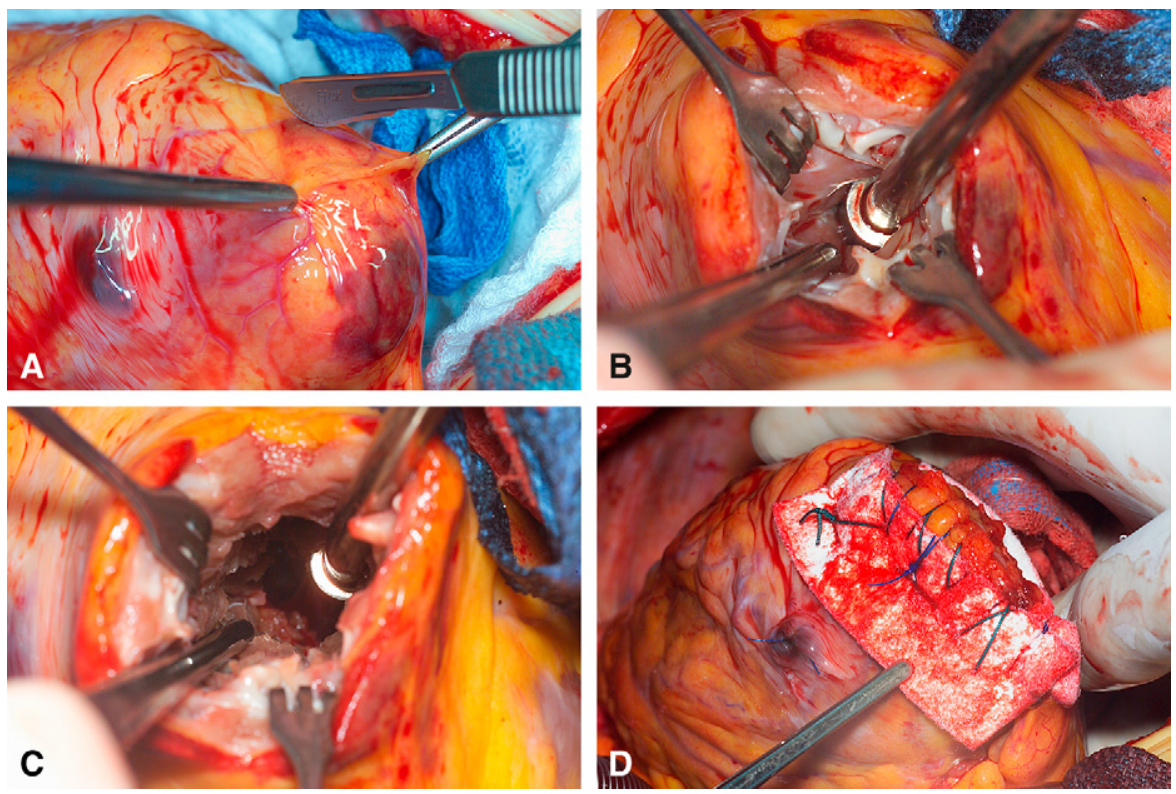

FIGURE 3. A and B, An incision made in the apex of the left ventricle (A) reveals the extensive muscle in the apex (B). C, Myectomy is performed to remove excess apical muscle. D, After myectomy, the incision is closed with felt strips.

was $72 \% \pm 7 \%$. The diagnosis of ApHCM was established in all patients by means of echocardiographic, angiographic, or MRI analysis; 7 patients also had evidence of subaortic LV outflow tract obstruction. No clinically significant coronary artery lesions requiring coronary artery bypass grafting were identified on preoperative coronary angiograms, but 2 patients had myocardial bridging of the left anterior descending artery.

Operative data are listed in Table 2. The mean mass of muscle removed from the LV was $15.7 \pm 6.8 \mathrm{~g}$. Concomitant procedures included tricuspid valve repair or replacement $(n=3)$, closure of the left atrial appendage $(n=4)$, the maze procedure $(\mathrm{n}=3)$, repair of myocardial bridging $(n=2)$, and mitral valve replacement $(n=1)$. Three patients required intra-aortic balloon support early after the operation, and $2(4.5 \%)$ patients died perioperatively. One death was related to severe bleeding and subsequent multiorgan failure. The second death occurred in a patient who had thrombosis of her mitral valve prosthesis and required emergency rereplacement. This second patient died as the result of neurologic injury resulting from shock before reoperation.

All 44 patients had a Swan-Ganz catheter placed during the operation, and 38 had complete hemodynamic measurements taken, including right heart pressures and cardiac output during anesthesia before sternal incision, at the time of sternal closure, and before catheter removal and discharge from the intensive care unit (Table 3).

Preoperative and early postoperative transthoracic echocardiograms were available for 39 patients, and late echocardiograms were available for 21 patients a mean of $2.3 \pm 2.1$ years after myectomy. In these 21 patients ejection fractions decreased from a mean of $72 \% \pm 8 \%$ preoperatively to $64 \% \pm 12 \%$ at dismissal and $61 \% \pm 12 \%$ at last followup (Figure 4). All patients had visible enlargement of the LV cavity.

Eleven patients had both preoperative and predismissal or late hemodynamic catheterization. The mean indexed LVEDV increased from $55 \pm 17$ to $68 \pm 18 \mathrm{~mL} / \mathrm{m}^{2}(P=$ $.003)$, and the mean indexed SV increased from $39 \pm 17$ to $46 \pm 13 \mathrm{~mL} / \mathrm{m}^{2}(P=.002$, Figure 5$)$. The mean estimated LV ejection fraction decreased on angiographic analysis from $71 \% \pm 8 \%$ to $65 \% \pm 8 \%(P=.06)$, whereas the mean left ventricular end-diastolic pressure decreased from $28 \pm 9$ to $24 \pm 6 \mathrm{~mm} \mathrm{Hg}(P=.007$, Figure 6$)$.

Preoperative and postoperative cardiac MRI were performed in 9 patients. The mean $\mathrm{LV}$ end-diastolic indexed volume increased by $13 \pm 16 \mathrm{~mL} / \mathrm{m}^{2}(P=.04)$, and the mean indexed LV SV increased by $3 \pm 9 \mathrm{~mL} / \mathrm{m}^{2}(P=.02)$.

Five patients underwent preoperative and late postoperative exercise testing with measurement of $\mathrm{VO}_{2 \max }$, as described previously. ${ }^{12}$ The mean preoperative $\mathrm{Vo}_{2 \max }$ of $13.5 \pm 4.4$ increased to $14.7 \pm 4.7(P=.004)$ at a median follow-up of 6.7 months (range, 5-28 months).

Functional status was available in $33(85 \%)$ of 39 alive patients, all but 1 of whom had initial improvement in symptoms; at last follow-up (mean, $3.2 \pm 3.3$ years), 23 (70\%) of these 33 patients were in New York Heart Association (NYHA) class I or II. All 8 patients reportedly in NYHA class III, and both of the patients in NYHA class IV had initial improvement in symptoms after the operation. The poor residual functional status in the majority of patients was believed to be due to either right heart failure, atrial 
TABLE 1. Characteristics of 44 patients who underwent apical myectomy

\begin{tabular}{|c|c|}
\hline Characteristic & No. $(\%)$ \\
\hline Women & $29(66)$ \\
\hline \multicolumn{2}{|l|}{ Race } \\
\hline White & $33(75)$ \\
\hline Black & $4(9)$ \\
\hline Middle Eastern & $1(2)$ \\
\hline Not identified & $6(14)$ \\
\hline NYHA class III or IV & $40(91)$ \\
\hline \multicolumn{2}{|l|}{ Symptoms } \\
\hline Shortness of breath & $44(100)$ \\
\hline Fatigue & $44(100)$ \\
\hline Angina & $27(61)$ \\
\hline Syncope or presyncope & $26(59)$ \\
\hline Palpitations & $18(41)$ \\
\hline \multicolumn{2}{|l|}{ History of arrhythmia } \\
\hline Atrial & $17(39)$ \\
\hline Ventricular & $5(11)$ \\
\hline Sinus rhythm & $37(84)$ \\
\hline Pacemaker & $4(9)$ \\
\hline ICD & $9(20)$ \\
\hline Family history of HCM & $10(23)$ \\
\hline $\begin{array}{l}\text { Prior cardiac transplant } \\
\text { consultation }\end{array}$ & $3(7)$ \\
\hline \multicolumn{2}{|l|}{ Medication } \\
\hline$\beta$-Blocker & $31(70)$ \\
\hline Calcium-channel blocker & $24(55)$ \\
\hline $\begin{array}{l}\text { Angiotensin-converting } \\
\text { enzyme inhibitor }\end{array}$ & $12(27)$ \\
\hline Diuretic & $20(45)$ \\
\hline Other antiarrhythmic & $9(20)$ \\
\hline
\end{tabular}

arrhythmias, or diastolic left heart failure. One patient underwent cardiac transplantation 4.7 years after apical myectomy. This patient had improvement in symptoms for 2 years after myectomy but subsequently had severe tricuspid regurgitation and profound right heart failure caused by a pacemaker lead. There were 2 late deaths (one from sudden cardiac arrest). The only patient whose symptoms did not improve after the operation died of unknown causes almost 3 years after the operation. Vital status was available at a mean follow-up of $2.6 \pm 3.1$ years (median, 1.3 years).

TABLE 2. Operative characteristics of 44 patients who underwent apical myectomy

\begin{tabular}{lc}
\hline \multicolumn{1}{c}{ Characteristic } & Value \\
\hline Cardiopulmonary bypass time (min) & $53.2 \pm 29.0$ \\
Crossclamp time (min) & $32.7 \pm 17.9$ \\
Mitral valve repair or replacement, $\mathrm{n}(\%)$ & $6(14)$ \\
Muscle mass removed $(\mathrm{g})$ & $15.7 \pm 6.8$ \\
Operative mortality, $\mathrm{n}(\%)$ & $2(4.5)$ \\
\hline Values are presented as means \pm standard deviations or numbers (percentages).
\end{tabular}

TABLE 3. Measurement of stroke volume by using a Swan-Ganz catheter in 38 patients who underwent apical myectomy

\begin{tabular}{lcc}
\hline Time of measurement & $\begin{array}{c}\text { Stroke volume } \\
(\mathbf{m L}) *\end{array}$ & $\boldsymbol{P}$ value $\dagger$ \\
\hline Before sternal split & $55.6 \pm 17.0$ & \\
At time of sternal closure & $56.5 \pm 19.3$ & .74 \\
Before ICU dismissal & $62.7 \pm 19.0$ & .01 \\
\hline$I C U$, Intensive care unit. *Values are means \pm standard deviations. $\dagger P$ values represent \\
a comparison with the measurement of stroke volume before sternal split.
\end{tabular}

Survival at 1,3 , and 5 years was $95 \%, 81 \%$, and $81 \%$, respectively (Figure 7).

Preoperatively, 4 patients had a permanent pacemaker (PPM), and 9 patients had an implantable cardioverter defibrillator (ICD) placed. Five other patients received an ICD in the perioperative period. In the follow-up period, 2 patients received a PPM, and 1 patient received an ICD. The patient who died of sudden cardiac arrest had neither a PPM nor an ICD.

Thirteen patients required rehospitalization subsequent to dismissal after the original procedure. Reasons for readmission included congestive heart failure $(n=6)$, stroke $(\mathrm{n}=2)$, transient ischemic attack $(\mathrm{n}=1)$, pulmonary embolism $(n=1)$, myocardial infarction $(n=1)$, gastrointestinal bleeding $(\mathrm{n}=1)$, and reoperation $(\mathrm{n}=1)$. The patient who required reoperation had severe tricuspid valve regurgitation. Heart failure persisted after tricuspid valve repair, and the patient eventually required heart transplantation.

\section{DISCUSSION}

Surgical treatment of patients with HCM consists mainly of subaortic myectomy to relieve the LV outflow tract obstruction that occurs in as many as $70 \%$ of patients. ${ }^{14-18}$ Medical therapy with $\beta$-blockers, calcium-channel blockers, ${ }^{14,15,17-20}$ or disopyramide ${ }^{21}$ might also reduce dynamic outflow gradients and improve symptoms in patients

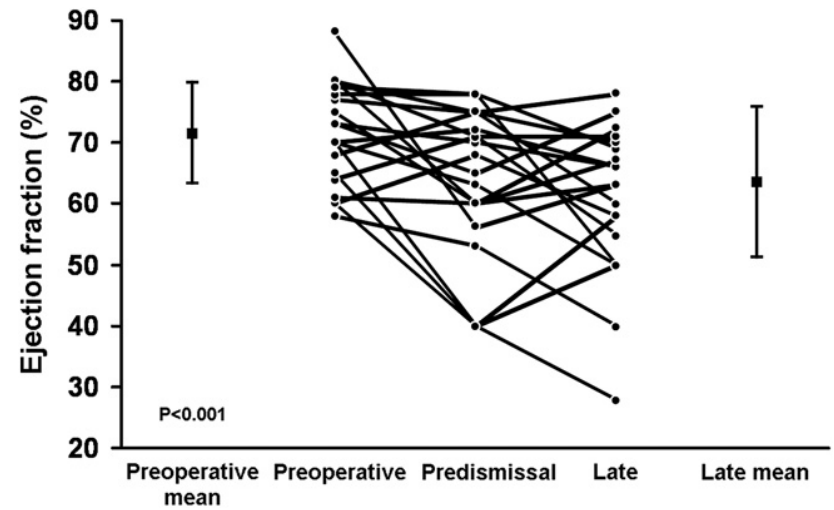

FIGURE 4. Echocardiographic measurements of ejection fraction before and after apical myectomy. Mean values are presented with standard deviations. The $P$ value was calculated for the change in mean ejection fraction. 

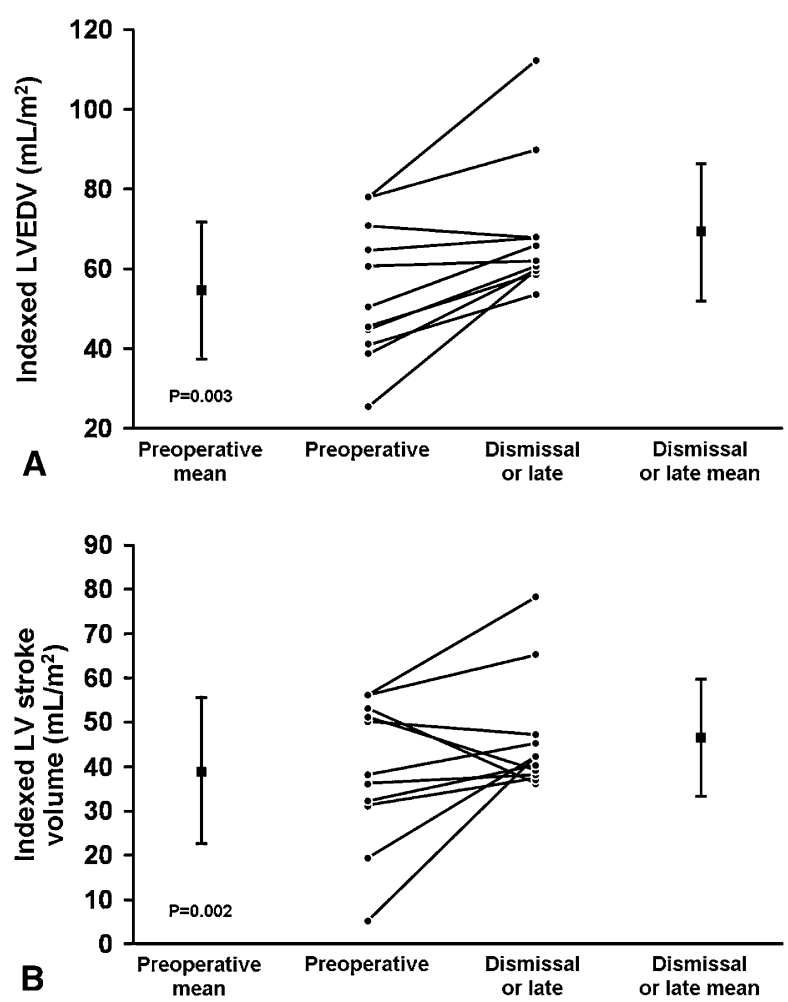

FIGURE 5. $A$ and $B$, Indexed left ventricular end-diastolic volume (LVEDV; A) and indexed left ventricular $(L V)$ stroke volume (B) in 11 patients who had both preoperative and postoperative hemodynamic catheterization measurements. Mean values are presented with standard deviations. The $P$ value was calculated for the change in mean indexed LVEDV and the change in indexed LV stroke volume.

who have obstructive HCM. However, the apical variant of HCM is generally not associated with subaortic obstruction, and symptoms, when present, respond poorly to medical therapy.

This report is the first to describe outcomes for patients treated with a novel surgical approach for ventricular remod-

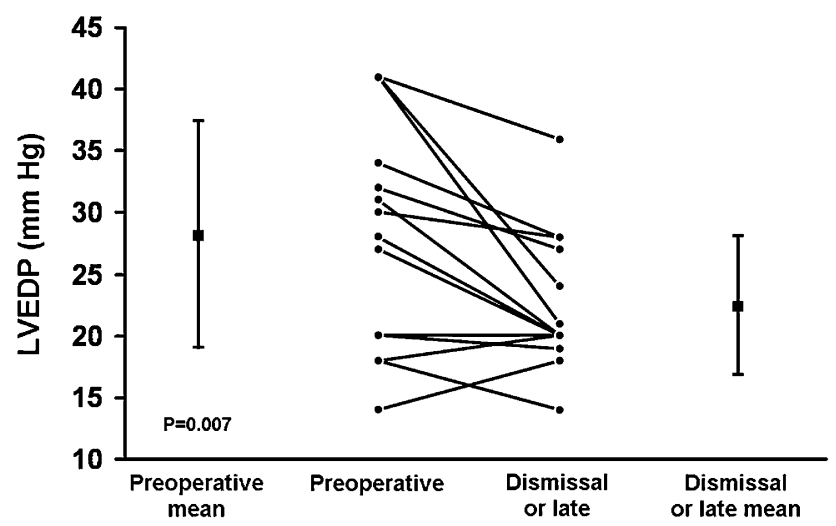

FIGURE 6. The change in left ventricular end-diastolic pressure (LVEDP) on preoperative and postoperative hemodynamic catheterization. Mean values are presented with standard deviations. The $P$ value was calculated for the change in mean LVEDP.

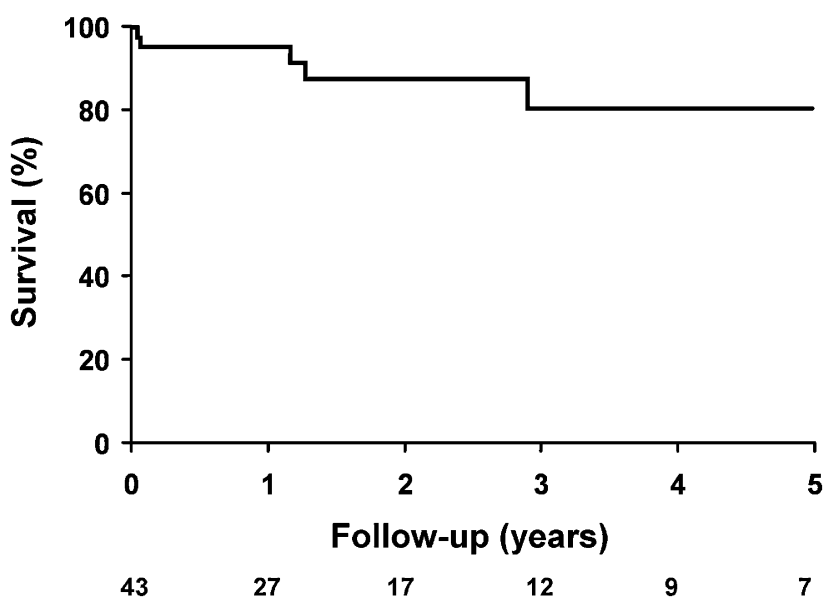

FIGURE 7. Kaplan-Meier curve of survival of patients after operations for apical hypertrophic cardiomyopathy.

eling in the management of symptomatic ApHCM. The procedure involves removal of hypertrophied muscle in the apical and middle regions of the LV, thus creating a larger chamber size in diastole. Although there might be mild hypokinesis in the region of the apical incision, overall contractility of the LV is preserved, with a resultant increase in the effective operative compliance of the LV that allows a larger filling volume without an increase in end-diastolic pressure. Indeed, in our patients measured SV increased after apical myectomy, and end-diastolic pressure was reduced. This hemodynamic improvement was accompanied by improvement in symptomatic status; all but 1 patient noted some postsurgical relief of dyspnea.

Diastolic dysfunction in patients with HCM results from a complex sequence of multiple interrelated events. ${ }^{17,22,23}$ Myocardial relaxation is impaired, as expected in any patient with HCM. However, patients with ApHCM have an anatomic limitation to diastolic filling. Severe hypertrophy at the apical and middle portions of the ventricle results in a small chamber size in the basal portion of the LV. The small volume of this chamber, in addition to the increase in muscle stiffness of the hypertrophied myocardium, results in a major decrease in the effective operative compliance of the $\mathrm{LV}^{24}$

Traditional treatment options for symptomatic patients with ApHCM have limited effectiveness. Medical therapy with $\beta$-blockers, calcium-channel blockers, and angiotensin-converting enzyme inhibitors has been proposed to improve LV diastolic filling. ${ }^{8,11}$ Although decreasing heart rate and reducing $\mathrm{LV}$ afterload might offer some theoretic benefit to hemodynamics and symptoms, most patients remain symptomatic or have symptom progression caused by the noncompliant hypertrophied LV. Dual-chamber pacing has not been effective in relieving symptoms in patients without outflow tract obstruction. ${ }^{25}$ Heart transplantation is the current treatment recommendation for patients with 
severe refractory heart failure caused by nonobstructive $\mathrm{HCM}$, including the apical variant. ${ }^{26}$ In addition, severe LV chamber hypertrophy might impede other surgical adjuncts, such as the placement of an LV assist device.

There are no detailed studies on the natural history of severely symptomatic patients with ApHCM. Indeed, most patients with this HCM phenotype are considered to have a benign prognosis, with good long-term survival and few symptoms. ${ }^{6-9}$ Eriksson and colleagues ${ }^{11}$ evaluated late outcomes for 105 patients with ApHCM and found a 15-year survival rate of $95 \%$, which is identical to that of an agematched and sex-matched cohort. With extended followup, however, the survival rates of $87 \%$ at 20 years and $79 \%$ at 25 years after diagnosis were lower than expected. In addition, some patients experienced fatigue, angina, dyspnea, arrhythmia, and even sudden death. Despite medical therapy, $20 \%$ of patients deteriorated in functional class, and 8 of the 105 patients progressed to NYHA class III or IV during follow-up. ${ }^{11}$ These symptomatic patients have no treatment options other than cardiac transplantation. In fact, in our series 3 patients were initially referred to the Mayo Clinic for evaluation for cardiac transplantation.

We observed no late complications from the apical incision used for myectomy and found no documented instances of ventricular arrhythmias that originated from scarring in this area. Ventricular tachycardia and sudden cardiac death are, however, associated with this form of HCM, and patients should be evaluated for risk of sudden death and for consideration of an ICD. ${ }^{12,13}$ The incisions were usually 5 to $6 \mathrm{~cm}$ in length and situated at the apex of the $\mathrm{LV}$, which is nonfunctional in patients with ApHCM. These incisions are smaller than those used for aneurysm repair or for other ventricular restoration procedures.

In addition to removal of an adequate volume of muscle, the procedure must avoid injury to the papillary muscles, which are displaced apically in patients with ApHCM. A limited initial ventriculotomy should first be made, and the anterolateral and posteromedial papillary muscles should be carefully identified before removal of large portions of myocardium. As the myectomy proceeds with removal of hypertrophied muscle from the apex, the enlarged papillary muscles can be shaved to further increase LV volume and to minimize the chance of residual midventricular obstruction.

Accurate assessment of the distribution of ventricular hypertrophy and LVEDV is critical to the identification of patients who might be helped by apical myectomy. The low normal (normal value, $30-50 \mathrm{~mL} / \mathrm{m}^{2}$ ) preoperative $\mathrm{SV}$ of our patients improved to a normal value postoperatively (mean, $46 \mathrm{~mL} / \mathrm{m}^{2}$ ); however, accuracy of volume assessment by any imaging study is limited by the abnormally shaped LV in patients with ApHCM. There are no commonly available validated corrections for imaging calculations of ventricular volume in patients with predominantly apical LV hypertrophy.
Some limitations of our findings should be mentioned. Detailed hemodynamic data were not available for all patients, and tests were performed as clinically indicated rather than per a study protocol. Early in this series, ventricular morphology was assessed by means of contrast ventriculographic analysis in some patients and by means of contrast echocardiographic analysis in select others; more recently, patients have had cardiac MRI to visualize the ventricular anatomy, but this imaging technique cannot be used in all patients for many reasons, including the presence of implantable devices. We further recognize that confounding factors, including a placebo effect, might have contributed to the improvement in symptoms we noted in our patients. Nevertheless, all but 1 patient had initial improvement in symptoms that lasted as long as 11 years, and only 1 patient had a progression of symptoms severe enough to warrant heart transplantation during the follow-up period.

\section{CONCLUSIONS}

A subset of patients with ApHCM present with severe limiting symptoms of dyspnea and fatigue caused by diastolic dysfunction and low cardiac output. Transapical ventricular myectomy to increase LVEDV improves diastolic function and SV. For patients with ApHCM who have limiting symptoms despite optimal medical treatment, this new procedure might be of benefit by improving hemodynamics and ameliorating symptoms.

\section{References}

1. Sakamoto T, Tei C, Murayama M, Ichiyasu H, Hada Y. Giant T wave inversion as a manifestation of asymmetrical apical hypertrophy (AAH) of the left ventricle. Echocardiographic and ultrasono-cardiotomographic study. Jpn Heart J. 1976; 17:611-29.

2. Yamaguchi H, Ishimura T, Nishiyama S, Nagasaki F, Nakanishi S, Takatsu F, et al. Hypertrophic nonobstructive cardiomyopathy with giant negative $\mathrm{T}$ waves (apical hypertrophy): ventriculographic and echocardiographic features in 30 patients. Am J Cardiol. 1979;44:401-12.

3. Maron BJ, Bonow RO, Seshagiri TN, Roberts WC, Epstein SE. Hypertrophic cardiomyopathy with ventricular septal hypertrophy localized to the apical region of the left ventricle (apical hypertrophic cardiomyopathy). Am J Cardiol. 1982;49: $1838-48$.

4. Maron BJ, Louie EK. Apical hypertrophic cardiomyopathy: a view from the U.S.A. J Cardiogr. 1986;16:513-7.

5. Louie EK, Maron BJ. Apical hypertrophic cardiomyopathy: clinical and twodimensional echocardiographic assessment. Ann Intern Med. 1987;106:663-70.

6. Webb JG, Sasson Z, Rakowski H, Liu P, Wigle ED. Apical hypertrophic cardiomyopathy: clinical follow-up and diagnostic correlates. J Am Coll Cardiol. 1990; 15:83-90.

7. Koga Y, Itaya K, Toshima H. Prognosis in hypertrophic cardiomyopathy. Am Heart J. 1984;108:351-9.

8. Keren G, Belhassen B, Sherez J, Miller HI, Megidish R, Berenfeld D, et al. Apical hypertrophic cardiomyopathy: evaluation by noninvasive and invasive techniques in 23 patients. Circulation. 1985;71:45-56.

9. Bertrand ME, Tilmant PY, Lablanche JM, Thieuleux FA. Apical hypertrophic cardiomyopathy: clinical and metabolic studies. Eur Heart J. 1983;4:127-33.

10. Lee CH, Liu PY, Lin LJ, Chen JH, Tsai LM. Clinical features and outcome of patients with apical hypertrophic cardiomyopathy in Taiwan. Cardiology. 2006; 106:29-35.

11. Eriksson MJ, Sonnenberg B, Woo A, Rakowski P, Parker TJ, Wigle ED, et al. Long-term outcome in patients with apical hypertrophic cardiomyopathy. $J$ Am Coll Cardiol. 2002;39:638-45. 
12. Abinader EG. Long-term outcome in patients with apical hypertrophic cardiomyopathy. J Am Coll Cardiol. 2002;40:837-8.

13. Ridjab D, Koch M, Zabel M, Schultheiss HP, Morguet AJ. Cardiac arrest and ventricular tachycardia in Japanese-type apical hypertrophic cardiomyopathy. Cardiology. 2007; 107:81-6.

14. Maron BJ, Bonow RO, Cannon RO III, Leon MB, Epstein SE. Hypertrophic cardiomyopathy. Interrelations of clinical manifestations, pathophysiology, and therapy (1). N Engl J Med. 1987;316:780-9.

15. Maron BJ, Bonow RO, Cannon RO III, Leon MB, Epstein SE. Hypertrophic cardiomyopathy. Interrelations of clinical manifestations, pathophysiology, and therapy (2). N Engl J Med. 1987;316:844-52.

16. Maron BJ, Spirito P, Green KJ, Wesley YE, Bonow RO, Arce J. Noninvasive assessment of left ventricular diastolic function by pulsed Doppler echocardiography in patients with hypertrophic cardiomyopathy. J Am Coll Cardiol. 1987;10: 733-42.

17. Wigle ED, Sasson Z, Henderson MA, Ruddy TD, Fulop J, Rakowski H, et al. Hypertrophic cardiomyopathy. The importance of the site and the extent of hypertrophy. A review. Prog Cardiovasc Dis. 1985;28:1-83.

18. Wigle ED. Hypertrophic cardiomyopathy: a 1987 viewpoint. Circulation. 1987; 75:311-22.

19. Bonow RO, Rosing DR, Bacharach SL, Green MV, Kent KM, Lipson LC, et al. Effects of verapamil on left ventricular systolic function and diastolic filling in patients with hypertrophic cardiomyopathy. Circulation. 1981;64:787-96.

20. Rosing DR, Kent KM, Maron BJ, Epstein SE. Verapamil therapy: a new approach to the pharmacologic treatment of hypertrophic cardiomyopathy. II. Effects on exercise capacity and symptomatic status. Circulation. 1979;60:1208-13.

21. Sherrid MV, Barac I, McKenna WJ, Elliott PM, Dickie S, Chojnowska L, et al. Multicenter study of the efficacy and safety of disopyramide in obstructive hypertrophic cardiomyopathy. J Am Coll Cardiol. 2005;45:1251-8.

22. Wigle ED. Impaired left ventricular relaxation in hypertrophic cardiomyopathy: relation to extent of hypertrophy. J Am Coll Cardiol. 1990;15:814-5.

23. Panidis IP, Nestico P, Hakki AH, Mintz GS, Segal BL, Iskandrian AS. Systolic and diastolic left ventricular performance at rest and during exercise in apical hypertrophic cardiomyopathy. Am J Cardiol. 1986;57:356-8.

24. Yamakado T, Hayashi T, Ohkubo S, Fukui A, Murayama S, Mori S, et al. Left ventricular diastolic function in apical hypertrophic cardiomyopathy. $J$ Cardiol. 1992;22:107-12.

25. Cannon RO III, Tripodi D, Dilsizian V, Panza JA, Fananapazir L. Results of permanent dual-chamber pacing in symptomatic nonobstructive hypertrophic cardiomyopathy. Am J Cardiol. 1994;73:571-6.

26. Biagini E, Spirito P, Leone O, Picchio FM, Coccolo F, Ragni L, et al. Heart transplantation in hypertrophic cardiomyopathy. Am J Cardiol. 2008;101:387-92.

\section{Discussion}

Dr Nicholas G. Smedira (Cleveland, Ohio). I have no disclosures. Dr Schaff, as usual, your presentation was clear and very informative, and I want to congratulate you on outstanding results. My first question relates to whether we are underestimating the prevalence of this disorder? We were taught 10 years ago that the incidence of obstruction in patients with hypertrophic obstructive cardiomyopathy was around $25 \%$. We now know that with provocative maneuvers, it is as high as $75 \%$. Are there more patients out there with this disorder than we are appreciating?

The second question relates to midcavitary obstruction, which you briefly described in the article. Do you require a specific gradient by your imaging study to identify those patients you would operate on, or do all these patients have a resting gradient, and if there is not a resting gradient, do you do provocative maneuvers, such as amyl nitrate, as we do with standard outflow tract obstruction?

You briefly mentioned that $30 \%$ of the patients had a decrease in functional status over 5 years, and in the article this was related to atrial arrhythmias and right ventricular dysfunction. Therefore I have a 2-part question. I have been very aggressive when treating atrial arrhythmias in patients who have hypertrophic obstructive cardiomyopathy. Are you more aggressive doing some ablative procedure in this cohort of patients? If you see a patient who has symptoms of right ventricular failure, would you now refer that patient directly to transplantation rather than the apical myectomy?

Thank you for this opportunity.

Dr Schaff. Your first question had to do with the prevalence of ApHCM. In our institution this subtype accounts for approximately $8 \%$ of the patients who come through the HCM clinic. There might be other patients with HCM and small cavities who might benefit from enlarging their ventricles.

The second question had to do with midventricular obstruction. It is important to recognize that you can access the midventricle through the apex easily, and this should be considered if midventricular obstruction remains after relief of subaortic obstruction.

The final question had to do with the development of atrial fibrillation, and we do combine maze procedures or pulmonary vein isolation with subaortic myectomy in patients who have HCM and troublesome atrial fibrillation. However, for patients who have atrial arrhythmias but are not in continuous atrial fibrillation, we are more conservative because prophylactic procedures can impair atrial transport function.

Dr Smedira. What about the right ventricle, right ventricular failure?

Dr Schaff. We do not have any special insights into indentifying patients who might have right ventricular failure, and this is an important issue.

Dr R. Duane Davis (Durham, NC). What do you think the true incidence is? Do you use magnetic resonance at all for quantification of and trying to determine where you think you will have benefit?

Dr Schaff. Well, it is hard to know what the true incidence is beyond the figures that I gave you. We do use cardiac magnetic resonance in these patients, but quantification of volumes is difficult because of ventricular morphology. You can see the cavity quite well, but most of the formulas to calculate ventricular volumes are based on a ventricular shape that these patients do not possess. It is important to develop or learn new methods for measuring ventricular volume with magnetic resonance or other techniques because, in my view, that is the key to identifying the patients who might benefit from this procedure. 